\title{
Synthesis and catalytic application of magnetic Co-Cu nanowires
}

\author{
Lijuan Sun, Xiaoyu Li, Zhiqiang Xu, Kenan Xie and Li Liao*
}

\author{
Letter \\ Address: \\ School of Chemical Engineering, Sichuan University, Chengdu \\ 610065, PR China \\ Email: \\ Li Liao* - liaolis@scu.edu.cn \\ * Corresponding author \\ Keywords: \\ catalyst; Co-Cu nanowires; liquid phase reduction; magnetic \\ materials; metal replacement
}

Beilstein J. Nanotechnol. 2017, 8, 1769-1773. doi:10.3762/bjnano.8.178

Received: 26 April 2017

Accepted: 08 August 2017

Published: 25 August 2017

Associate Editor: R. Xu

(C) 2017 Sun et al.; licensee Beilstein-Institut.

License and terms: see end of document.

\begin{abstract}
A rapid, template-free method was developed to prepare magnetic, bimetallic $\mathrm{Co}-\mathrm{Cu}$ nanowires via liquid phase reduction and metal replacement under an external magnetic field. The characterization results confirmed that the as-prepared product was bimetallic $\mathrm{Co}-\mathrm{Cu}$ nanowires with a desirable linear structure. Additionally, the magnetic hysteresis loop showed that the bimetallic $\mathrm{Co}-\mathrm{Cu}$ nanowires were paramagnetic, which meant they could be easily separated from the reaction mixture. Furthermore, they were applied to the hydrolysis system of ammonia borane as a catalyst for the first time. More importantly, the catalysis results showed that the bimetallic nanowires possessed appealing catalytic performance. Therefore, a rapid and facile synthesis method is introduced which is capable of preparing bimetallic $\mathrm{Co}-\mathrm{Cu}$ nanowires with great potential for industrial applications.
\end{abstract}

\section{Findings}

In recent years, many researchers have been devoted to the preparation and characterization of $\mathrm{Co}-\mathrm{Cu}$ nanowires due to its significant magnetic [1-6] and chemical properties [7]. However, it is worth noting that there are only few papers which report on the application of $\mathrm{Co}-\mathrm{Cu}$ nanowires.

At present, the primary synthetic method for $\mathrm{Co}-\mathrm{Cu}$ nanowires is mainly electrodeposition by different templates, as found in the previous literature. For example, many papers have reported $\mathrm{Co}-\mathrm{Cu}$ nanowires electrodeposited into a porous anodic

aluminum oxide template [1-4]. Additionally, L. Gravier et al. [8] prepared $\mathrm{Co}-\mathrm{Cu}$ multilayered nanowires by electrodeposition in a polymer matrix. However, the electrodeposition method using templates increases the cost of production and the complexity of the synthetic process. Thus, it is necessary to devote attention to the development of a facile method for the preparation of $\mathrm{Co}-\mathrm{Cu}$ nanowires.

In the present paper, bimetallic $\mathrm{Co}-\mathrm{Cu}$ nanowires with a highly desirable linear structure were successfully synthesized via a 
rapid and facile template-free method [9-11] assisted by magnetic fields. Moreover, they were applied to catalyze the hydrolysis of ammonia borane $\left(\mathrm{NH}_{3}-\mathrm{BH}_{3}, \mathrm{AB}\right)$ for the first time. This result lays the foundation for expanding their application to industrial catalysis.

All chemicals were of analytical reagent grade and used without any further purification. $\mathrm{CoCl}_{2} \cdot 6 \mathrm{H}_{2} \mathrm{O}$, EDTA-2Na, $\mathrm{CuSO}_{4} \cdot 5 \mathrm{H}_{2} \mathrm{O}$, PVP, $\mathrm{NaOH}, \mathrm{N}_{2} \mathrm{H}_{4} \cdot \mathrm{H}_{2} \mathrm{O}, \mathrm{H}_{2} \mathrm{PtCl}_{6} \cdot 6 \mathrm{H}_{2} \mathrm{O}$ and $\mathrm{C}_{2} \mathrm{H}_{5} \mathrm{OH}$ were purchased from Chengdu Kelong Reagent Co. Ltd (China). $\mathrm{H}_{3} \mathrm{NBH}_{3}$ was supplied from Aladdin (Shanghai, China). Deionized water was used in all aqueous solutions.

The following reactions took place between two parallel neodymium magnets $\left(60 \times 30 \times 10 \mathrm{~mm}^{3}\right)$ separated $150 \mathrm{~mm}$ apart. The magnetic intensity inside the reaction solution was approximately $40 \mathrm{mT}$ as measured by a magnetometer. The detailed synthetic process for the $\mathrm{Co}-\mathrm{Cu}$ nanowires was as follows. First, $0.14 \mathrm{~g}$ of $\mathrm{CoCl}_{2} \cdot 6 \mathrm{H}_{2} \mathrm{O}$ and $0.22 \mathrm{~g}$ of EDTA-2Na were dispersed in $60 \mathrm{~mL}$ of deionized water in a $100 \mathrm{~mL}$ polytetrafluoroethylene (PTFE) beaker. Then $0.18 \mathrm{~g}$ of PVP was added to the reaction solution. The $\mathrm{pH}$ value of the solution was adjusted to 14 by adding $2 \mathrm{~g}$ of $\mathrm{NaOH}$, and the temperature of solution was kept at $80{ }^{\circ} \mathrm{C}$. Afterwards, $0.1 \mathrm{~mL}$ of $80 \mathrm{wt} \%$ $\mathrm{N}_{2} \mathrm{H}_{4} \cdot \mathrm{H}_{2} \mathrm{O}$ and $0.12 \mathrm{~mL}$ of $0.0253 \mathrm{~mol} \cdot \mathrm{L}^{-1} \mathrm{H}_{2} \mathrm{PtCl}_{6} \cdot 6 \mathrm{H}_{2} \mathrm{O}$ were added to the solution with gentle stirring. Ultimately, the reaction was over after about $5 \mathrm{~min}$, and the product of Co nanowires was collected and rinsed three times with deionized water and ethanol, respectively. Next, $0.3 \mathrm{~mL}$ of $80 \mathrm{wt} \% \mathrm{~N}_{2} \mathrm{H}_{4} \cdot \mathrm{H}_{2} \mathrm{O}$ were added to the cobalt nanowires with $60 \mathrm{~mL}$ of deionized water in a glass beaker, and heated in a water bath at a stationary temperature of $80^{\circ} \mathrm{C}$. Additionally, $0.015 \mathrm{~g}$ of $\mathrm{CuSO}_{4} \cdot 5 \mathrm{H}_{2} \mathrm{O}$ (the starting molar ratio was $\mathrm{Co} / \mathrm{Cu} 10: 1$ ) was dissolved in the glass beaker with continued stirring. Finally, after about $5 \mathrm{~min}$, the product was separated from the reaction mixture by neodymium magnets. Similarly, the product of bimetallic $\mathrm{Co}-\mathrm{Cu}$ nanowires was rinsed three times by deionized water and ethanol.
For the catalytic hydrolysis of $\mathrm{AB}, 10 \mathrm{~mL}$ of deionized water and $0.005 \mathrm{~g}$ of $\mathrm{Co}-\mathrm{Cu}$ nanowires were added to a Florence flask and heated at $50{ }^{\circ} \mathrm{C}$ in a water bath. Furthermore, $0.023 \mathrm{~g}$ of $\mathrm{AB}$ was dissolved in the Florence flask with ultrasonic stirring. Ultimately, the volume of hydrogen was monitored by a eudiometer.

The morphology and crystal structure of the products were observed by scanning electron microscopy (SEM, Hitachi S4800), transmission electron microscopy (TEM, FEI Tecnai G20 S-TWIN) and X-ray diffraction (XRD, Rigaku D/max 2200pc, $\mathrm{Cu} \mathrm{K} \alpha$, step size $4 \% \mathrm{~min}$ ). The composition and amount of the sample was characterized by energy-dispersive X-ray spectroscopy (EDS, Oxford Instruments, X-Max 51-XMX0019). The magnetic performance of the sample was studied by a vibrating sample magnetometer (VSM, Lake Shore Cryotronics Inc., 7400).

Figure 1 compares the difference between the $\mathrm{Co}-\mathrm{Cu}$ nanowire synthesis with and without application of an external magnetic field. It was very evident that the linear structure of the $\mathrm{Co}-\mathrm{Cu}$ nanowires prepared without an external magnetic field was undesirable. Moreover, the $\mathrm{Co}-\mathrm{Cu}$ nanowires prepared without an external magnetic field resulted in intense aggregation of products, which was found to be a limitation for catalytic applications.

The SEM and TEM images exhibiting the surface morphology of bimetallic $\mathrm{Co}-\mathrm{Cu}$ nanowires at different magnification are given in Figure 2. It was obvious that bimetallic $\mathrm{Co}-\mathrm{Cu}$ nanowires were arranged into long, straight nanowires with smooth surfaces. The average diameter of the nanowires was about $150 \mathrm{~nm}$, which can be observed in Figure 2b,d.

Figure 3 shows XRD and HRTEM patterns of the as-prepared bimetallic $\mathrm{Co}-\mathrm{Cu}$ nanowires. In Figure 3a, two characteristic peaks of face-centered cubic Co at $2 \theta$ values $44.216^{\circ}$ and $75.853^{\circ}$ corresponded to Miller indices of (111) and (220), re-

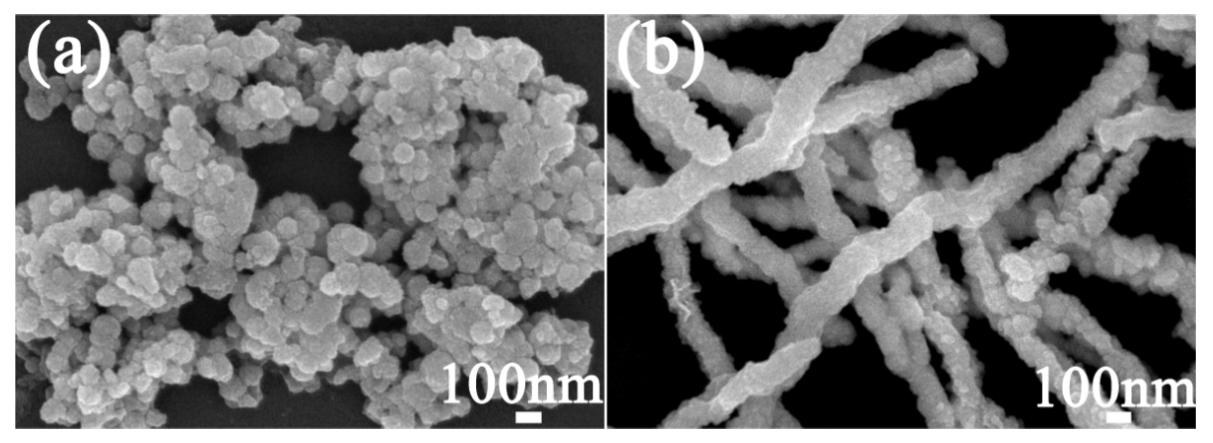

Figure 1: SEM images of bimetallic Co-Cu nanowires (a) without an external magnetic field and (b) with an external magnetic field. 


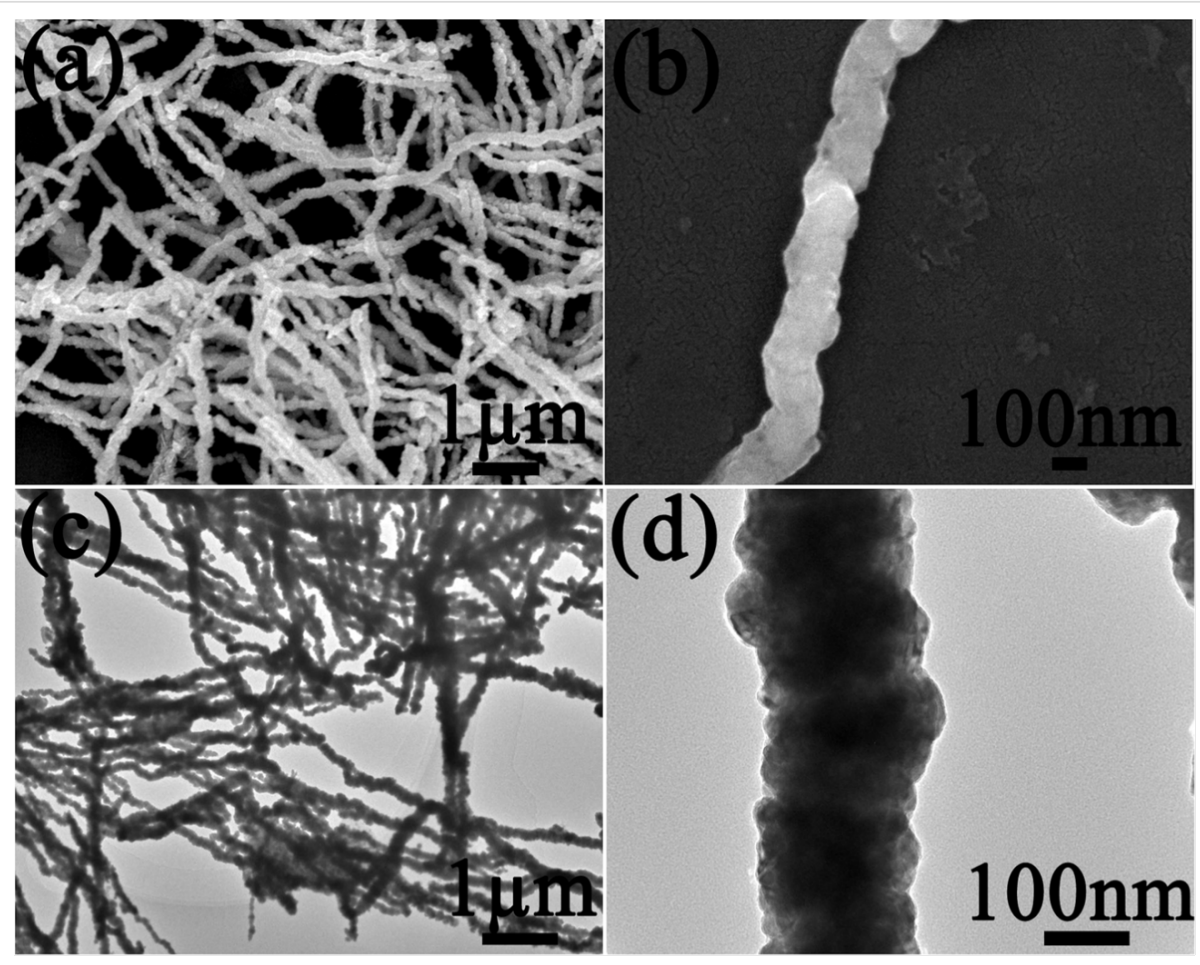

Figure 2: SEM (a) and magnified SEM (b) images as well as TEM (c) and magnified TEM (d) images of bimetallic Co-Cu nanowires at different magnifications.

spectively. Additionally, the characteristic peak of face-centered cubic $\mathrm{Cu}$ is at $2 \theta=43.297^{\circ}$ and is ascribed to Miller indices of (111). Finally, the XRD spectrum indicated the product was only made up of face-centered cubic $\mathrm{Co}$ and $\mathrm{Cu}$ without any impurity peaks; therefore, the product was confirmed to be bimetallic $\mathrm{Co}-\mathrm{Cu}$ nanowires. Furthermore, The HRTEM pattern in Figure 3b showed that the two types of lattice spacings for Co were about $0.20 \mathrm{~nm}$ and $0.13 \mathrm{~nm}$, which were in excellent agreement with (111) and (220) lattice planes of face-centered cubic $\mathrm{Co}$, respectively. Moreover, the lattice spacing of $\mathrm{Cu}$ was about $0.21 \mathrm{~nm}$, which was consistent with the (111) lattice plane of face-centered cubic $\mathrm{Cu}$. Hence, the components of the bimetallic $\mathrm{Co}-\mathrm{Cu}$ nanowires were further confirmed through the HRTEM result.

In order to further analyze the composition of the freshly prepared sample, EDS spectra and elemental mapping profiles of as-prepared bimetallic $\mathrm{Co}-\mathrm{Cu}$ nanowires were taken as exhibited in Figure 4. Figure 4a shows the measurement selected area of the bimetallic $\mathrm{Co}-\mathrm{Cu}$ nanowires, and Figure $4 \mathrm{~b}$ shows the detailed elemental spectrum corresponding to the selected area. Figure $4 \mathrm{~b}$ shows that the as-prepared product contained
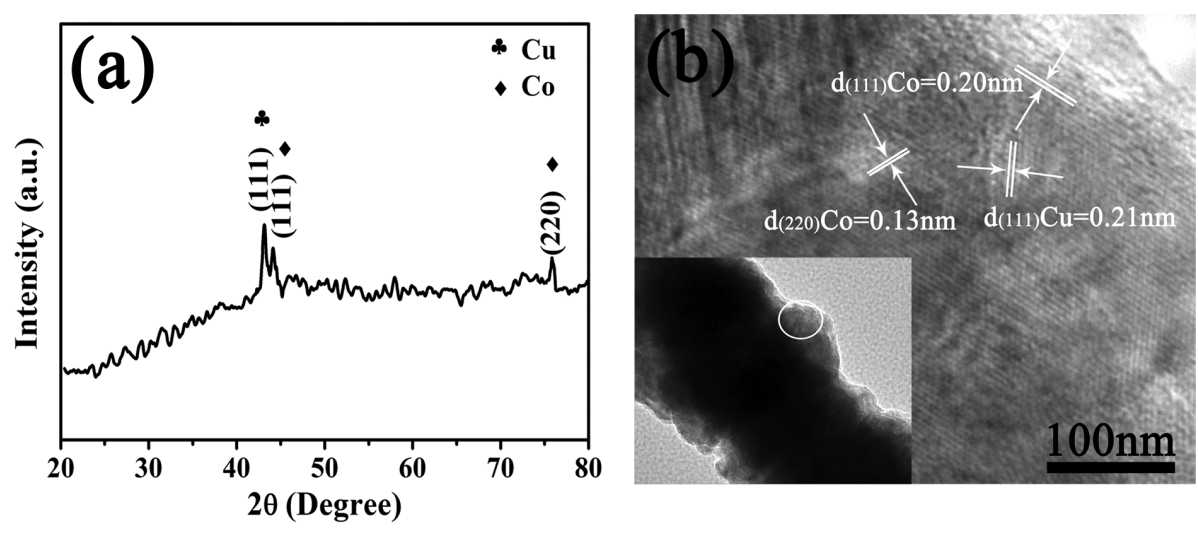

Figure 3: (a) XRD pattern and (b) HRTEM pattern of bimetallic Co-Cu nanowires. 




Figure 4: (a) SEM image and corresponding (b) EDS spectra of bimetallic Co-Cu nanowires, and elemental mapping profiles of (c) Co and (d) Cu.

elemental cobalt as well as elemental copper, which is in accordance with the XRD patterns. Additionally, silicon, carbon and platinum peaks were from the calculation of the elementary composition because they originated from the silicon wafer substrate, $\mathrm{PVP}$ and $\mathrm{H}_{2} \mathrm{PtCl}_{6} \cdot 6 \mathrm{H}_{2} \mathrm{O}$, respectively. Moreover, the elemental mapping profiles (Figure $4 \mathrm{c}, \mathrm{d}$ ) of $\mathrm{Co}$ and $\mathrm{Cu}$ further proved the presence of $\mathrm{Co}$ and $\mathrm{Cu}$ as well as their uniform distribution patterns.

The magnetic hysteresis loop of bimetallic $\mathrm{Co}-\mathrm{Cu}$ nanowires was measured under an applied magnetic field of up to 20,000 Oe at room temperature, and the variation of the magnetization versus magnetic field is exhibited in Figure 5a. The coercivity $\left(H_{\mathrm{c}}\right)$, saturation magnetization $\left(M_{\mathrm{S}}\right)$ and remnant magnetization $\left(M_{\mathrm{r}}\right)$ were $480.30 \mathrm{Oe}, 90.47 \mathrm{emu} \cdot \mathrm{g}^{-1}$ and $25.50 \mathrm{emu} \cdot \mathrm{g}^{-1}$, respectively. The appearance of a hysteresis loop demonstrated that the bimetallic $\mathrm{Co}-\mathrm{Cu}$ nanowires possessed paramagnetism [12]. Therefore, the bimetallic $\mathrm{Co}-\mathrm{Cu}$ nanowires could be easily separated from the solution by providing an external magnetic field.

Figure $5 \mathrm{~b}$ shows the plots of evolution of $\mathrm{H}_{2}$ vs time for the hydrolysis of $\mathrm{AB}$ using bimetallic $\mathrm{Co}-\mathrm{Cu}$ nanowires as a catalyst and the activity in terms of turnover frequency (TOF) [13] was calculated to be $6.17\left(\mathrm{~mol} \mathrm{H} 2 \cdot \mathrm{min}^{-1} \cdot(\mathrm{mol} \mathrm{Co}-\mathrm{Cu})^{-1}\right)$. Furthermore, bimetallic $\mathrm{Co}-\mathrm{Cu}$ nanowires could be separated easily from the catalytic system due to their inherent magnetic properties. Therefore, it was convenient to recycle them for the
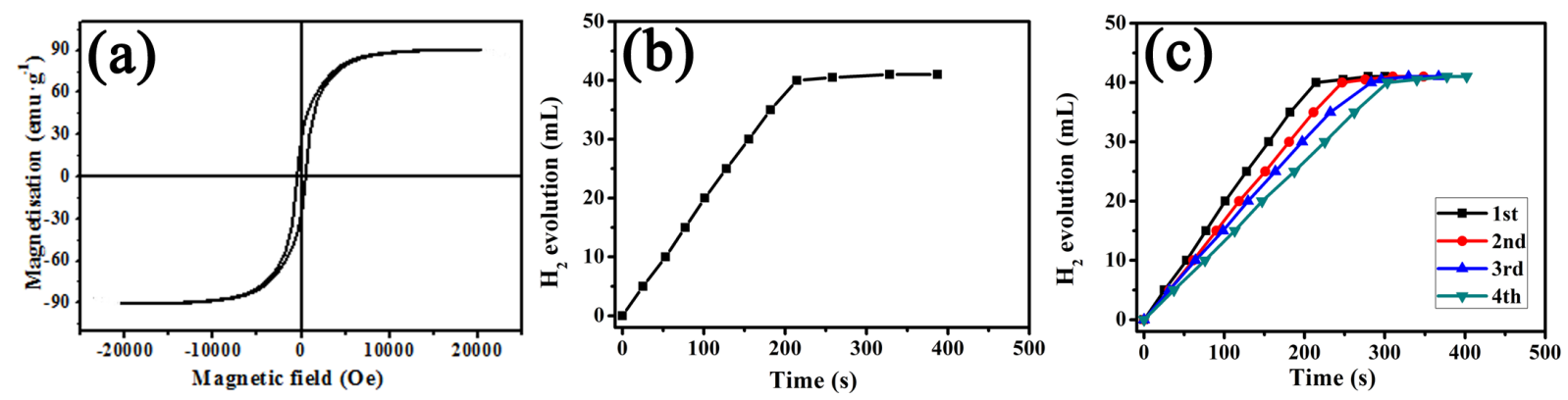

Figure 5: (a) Magnetic hysteresis loop of bimetallic Co-Cu nanowires, (b) time plots of catalytic hydrolysis of $A B$ and (c) hydrogen generation from $A B$ catalyzed by bimetallic Co-Cu nanowires from the 1 st to 4 th cycles. 
hydrolysis of $\mathrm{AB}$. The recyclability of bimetallic $\mathrm{Co}-\mathrm{Cu}$ nanowires up to the fourth run for hydrolysis of $\mathrm{AB}$ is shown in Figure $5 \mathrm{c}$. Finally, the catalyst retained $70 \%$ of its initial catalytic activity in the fourth run.

Table 1 compares the catalytic activity in terms of TOF values of different catalysts used for the hydrolysis of $\mathrm{AB}$. It is clear that $\mathrm{Co}-\mathrm{Cu}$ nanowires possess enhanced performance as compared to the other catalysts listed in Table 1, and they were much less expensive than these precious metal material based catalysts. Therefore, $\mathrm{Co}-\mathrm{Cu}$ nanowires show a great promise in the prospect of catalytic systems.

\begin{tabular}{l}
$\begin{array}{l}\text { Table 1: Catalytic activity of different catalysts used for the hydrolysis } \\
\text { of AB. }\end{array}$ \\
\begin{tabular}{lll} 
Catalyst & $\begin{array}{l}\text { TOF } \\
\left(\mathrm{mol} \mathrm{H}_{2} \cdot \mathrm{min}^{-1} \cdot(\mathrm{mol}\right. \\
\left.\text { catalyst })^{-1}\right)\end{array}$ & Ref. \\
& 6.25 & \\
\hline RGO/Pd & 6.17 & {$[14]$} \\
Co-Cu NWs & 6.0 & this work \\
AuCo alloy & 4.5 & {$[15]$} \\
PVP-stabilized Ni NPs & {$[16]$} \\
intrazeolite cobalt(0) NCs & 2.4 & {$[17]$}
\end{tabular} \\
\hline
\end{tabular}

\section{Conclusion}

In summary, magnetic bimetallic $\mathrm{Co}-\mathrm{Cu}$ nanowires were successfully synthesized by a rapid, inexpensive, template-free method under an external magnetic field for the first time. The SEM and TEM results showed that the as-prepared product possessed a highly desirable, linear structure, and the average diameter was about $150 \mathrm{~nm}$. Moreover, the magnetic hysteresis loop indicated that bimetallic $\mathrm{Co}-\mathrm{Cu}$ nanowires were paramagnetic materials, which meant they could be separated easily from the reaction mixture. Furthermore, the product was successfully applied to the hydrolysis of $\mathrm{AB}$ as a catalyst for the first time, and the activity in terms of TOF was calculated to be $6.17\left(\mathrm{~mol} \mathrm{H}_{2} \cdot \mathrm{min}^{-1}\right.$. $\left.(\mathrm{mol} \mathrm{Co}-\mathrm{Cu})^{-1}\right)$. Therefore, a rapid and facile synthesis method was developed to prepare bimetallic $\mathrm{Co}-\mathrm{Cu}$ nanowires with great potential for industrial applications.

\section{Acknowledgements}

This work was funded by the National Natural Science Foundation of China (No. 50904046).

\section{References}

1. Cho, J. U.; Liu, Q. X.; Min, J. H.; Ko, S. P.; Kim, Y. K. J. Magn. Magn. Mater. 2006, 304, e213-e215. doi:10.1016/j.jmmm.2006.02.034
2. Yong, R.; Jian-Bo, W.; Qing-Fang, L.; Xiang-Hua, H.; De-Sheng, X. Chin. Phys. B 2009, 18, 3573-3576. doi:10.1088/1674-1056/18/8/073

3. Javed, K.; Shi, D. W.; Ali, S. S.; Jiang, J.; Liu, P.; Han, X. F. IEEE Trans. Magn. 2014, 50, 1-4. doi:10.1109/TMAG.2014.2310056

4. Song, Z.; Xie, Y.; Yao, S.; Wang, H.; Zhang, W.; Tang, Z. Mater. Lett. 2011, 65, 1562-1564. doi:10.1016/j.matlet.2011.02.079

5. Miyazakia, K.; Kainuma, S.; Hisatake, K.; Watanabe, T.; Fukumuro, N. Electrochim. Acta 1999, 44, 3713-3719. doi:10.1016/S0013-4686(99)00075-4

6. Cho, J. U.; Wu, J.-H.; Min, J. H.; Lee, J. H.; Liu, H.-L.; Kim, Y. K. J. Magn. Magn. Mater. 2007, 310, 2420-2422. doi:10.1016/j.jmmm.2006.10.809

7. Ghosh, S. K. Electrochim. Acta 2008, 53, 8070-8077. doi:10.1016/j.electacta.2008.06.019

8. Gravier, L.; Fábián, A.; Rudolf, A.; Cachin, A.; Wegrowe, J.-E.; Ansermet, J.-P. J. Magn. Magn. Mater. 2004, 271, 153-158. doi:10.1016/j.jmmm.2003.09.022

9. Li, X.; Wang, H.; Xie, K.; Long, Q.; Lai, X.; Liao, L. Beilstein J. Nanotechnol. 2015, 6, 2123-2128. doi:10.3762/bjnano.6.217

10. Wang, H.; Li, X.; Li, M.; Xie, K.; Liao, L. Beilstein J. Nanotechnol. 2015, 6, 1268-1271. doi:10.3762/bjnano.6.130

11. Li, X.; Sun, L.; Wang, H.; Xie, K.; Long, Q.; Lai, X.; Liao, L. Beilstein J. Nanotechnol. 2016, 7, 990-994. doi:10.3762/bjnano.7.91

12. Senapati, S.; Srivastava, S. K.; Singh, S. B.; Biswas, K. Cryst. Growth Des. 2010, 10, 4068-4075. doi:10.1021/cg100740e

13. Yang, L.; Cao, N.; Du, C.; Dai, H.; Hu, K.; Luo, W.; Cheng, G. Mater. Lett. 2014, 115, 113-116. doi:10.1016/j.matlet.2013.10.039

14. Xi, P.; Chen, F.; Xie, G.; Ma, C.; Liu, H.; Shao, C.; Wang, J.; Xu, Z.; Xu, X.; Zeng, Z. Nanoscale 2012, 4, 5597-5601. doi:10.1039/c2nr31010d

15. Yan, J.-M.; Zhang, X.-B.; Akita, T.; Haruta, M.; Xu, Q. J. Am. Chem. Soc. 2010, 132, 5326-5327. doi:10.1021/ja910513h 16. Özhava, D.; Kılıçaslan, N. Z.; Özkar, S. Appl. Catal., B: Environ. 2015, 162, 573-582. doi:10.1016/j.apcatb.2014.07.033

17. Rakap, M.; Özkar, S. Int. J. Hydrogen Energy 2010, 35, 3341-3346. doi:10.1016/j.ijhydene.2010.01.138

\section{License and Terms}

This is an Open Access article under the terms of the Creative Commons Attribution License (http://creativecommons.org/licenses/by/4.0), which permits unrestricted use, distribution, and reproduction in any medium, provided the original work is properly cited.

The license is subject to the Beilstein Journal of Nanotechnology terms and conditions: (http://www.beilstein-journals.org/bjnano)

The definitive version of this article is the electronic one which can be found at: doi:10.3762/bjnano.8.178 